\title{
Apparent Mineralocorticoid Excess: Research as an Art Form
}

\author{
John W. Funder ${ }^{1}$ \\ Published online: 29 September 2020 \\ (c) Springer Science+Business Media, LLC, part of Springer Nature 2020
}

This issue of the Journal contains a remarkable paper from China, entitled "Apparent Mineralocorticoid Excess caused by Novel Compound Heterozygous Mutations in HSDB11 and Characterised by Early onset Hypertension and Hypokalemia". In the very first line of the Abstract the authors begin with "Apparent Mineralocorticoid Excess is an ultra rare Autosomal Recessive Disorder...", and continue to document their case, number 101 in the world over 30 years. For many readers of the journal, a prevalence of $\sim 3$ cases per year, often but not always the product of a consanguineous union, may be something to skip over, or to scan read at best. This would be a mistake for a series of reasons, which I will address later in this editorial review: first, however, the back story.

Forty-five years a young native American girl from the Zuni tribe in Arizona was referred to the eminent-and still practising-New York paediatric endocrinologist Dr. Maria New. The girl was extremely hypertensive, despite very low levels of renin and aldosterone. Over the months in New York she was extensively investigated by Dr. New and the late Dr. Stanley Ulick to determine the cause of her condition: in that it was to some extent ameliorated by spironolactone it was thought that it might be caused by an unknown highly active mineralocorticoid [1]. They sent blood and urine samples to the late John Baxter in San Francisco, and to me in Melbourne: neither of us could find anything that would fill the bill. The description of the syndrome was published in 1977, and the first coinage of "Apparent Mineralocorticoid Excess" used in a second paper in 1979 [2]: the latter ascribed the aetiology of her condition to defects in the peripheral metabolism of cortisol.

Apparent Mineralocorticoid Excess remained an enigma for the following decade, until in 1988 the publication of

John W. Funder

john.funder@hudson.org.au

1 Monash University and the Hudson Institute, 27-31 Wright Street, Clayton 3168 VIC, Australia two papers [3, 4] characterising the enzyme (11BHSD2) responsible for allowing aldosterone to selectively activate renal tubular mineralocorticoid receptors, in the face of 100fold higher free plasma concentrations of cortisol, despite the latter having the same affinity as aldosterone for mineralocorticoid receptors. These studies got it half rightwhich fortunately was sufficient for Apparent Mineralocorticoid Excess-by assuming that 11BHSD2 was able to metabolise all the incident cortisol to receptor-inactive cortisone. Given that the kidneys receive $20 \%$ of cardiac output, that the circulation time is $1 \mathrm{~min}$, and that the halftime of cortisol is $\sim 30 \mathrm{~min}$, this is clearly not the case-and that the answer lies elsewhere, in the conversion of the cosubstrate NAD to NADH. What clearly is the case is that the selectivity-conferring effect of 11BHSD2 can be disrupted by external agents—e.g. licorice—or at the genetic level, as is the case in Apparent Mineralocorticoid Excess.

One of the reasons that the paper is remarkable is that in addition to their identifying two novel mutations in 11BHSD2 in a patient with heterozygous apparent mineralocorticoid excess is the sheer extent of the authors' approach. They used next generation sequencing not only on the 17-year-old proband, but on three generations of relatives. They scanned 100 hypertensives and 100 healthy controls, in whom none of the identified variants were found.

The second reason is the extent of the protein modelling, given that the crystal structure of 11BHSD2 has not been solved. The authors used as a template a homologous 11BHSD1 crystal structure, to compute a putative model of the structure of the mutant 11BHSD2 molecules. Using this structure, they show that the mutations "...not only disturb the action between nearby amino acid residues, but also affect the stability of NADP and the substrate in the binding site, thus leading to loss of enzyme activity". The NADP is a hangover from 11BHSD1; the cosubstrate in the cortisol to cortisone reaction catalysed by 11BHSD2 is NAD.

The third reason is their discussion, of this addition to the canon of now 101 subjects with Apparent Mineralocorticoid 
Excess and then across the field. The discussion is linear, matter-of-fact, generous and restrained. The authors have been meticulous in their parsing of all English-language manuscripts - up until the end of February 2020 - which mention Apparent Mineralocorticoid Excess: Supplementary Fig. 1 is worth the wait until it comes up, at least on my venerable desktop computer. Supplementary Table 1 lists all the genes-84 of them-used in the comparison panel for next generation sequencing, a detail often assumed or overlooked in many next generation sequencing studies.

There is a fourth reason, and a fifth. The fourth reason is that what we have here is not just a scientific paper, but a work of art. Even if you could not care less about Apparent Mineralocorticoid Excess scan it; and make sure your fellows and students, even if they are in thyroid or diabetes, read it and are moved to try and emulate it. Most very good papers are like Toyotas or Volkswagens, which are very good cars; this is a Maserati.

The final reason to celebrate this paper is its recognition of the universality of our scientific endeavours, their timelessness, and the way in which they can and must transcend the politics of relative advantage. The authors of this remarkable paper clearly realise this to be the case-and for their science, their consummate artistry, and the sharing of their discovery we are all very much in their debt.
Funding Supported by the Victorian Government's Operational Infrastructure Support Program.

\section{Compliance with ethical standards}

Conflict of interest The author declares that he has no conflict of interest.

Publisher's note Springer Nature remains neutral with regard to jurisdictional claims in published maps and institutional affiliations.

\section{References}

1. M.I. New, I.S. Levine, E.G. Biglieri, J. Pariera, S. Ulick, Evidence for an unidentified steroid in a child with apparent mineralocorticold hypertension. J. Clin. Endocrinol. Metab. 44, 942-953 (1977)

2. S. Ulick, L. Levine, P. Gunczalar, I.C. Ramirez, W. Rauh, A. Rosier, H.L. Bradlow, M.,I. New, A syndrome of apparent mineralocorticoid excess associated with defects in the peripheral metabolism of cortisol. J. Clin. Endocrinol. Metab. 49, 757-764 (1979)

3. J.W. Funder, P.T. Pearce, R. Smith, A.I. Smith, Mineralocorticoid action: target-tissue specificity is enzyme, not receptor, mediated. Science 242, 583-585 (1988)

4. C.R.W. Edwards, P.M. Stewart, D. Burt, L. Brett, M.A. McIntyre, W.S. Sutanto, E.R. de Kloet, C. Monder, Localisation of 11 beta hydroxysteroid dehydrogenase-tissue-specific protector of the mineralocorticoid receptor. Lancet ii. 986-988 (1988) 